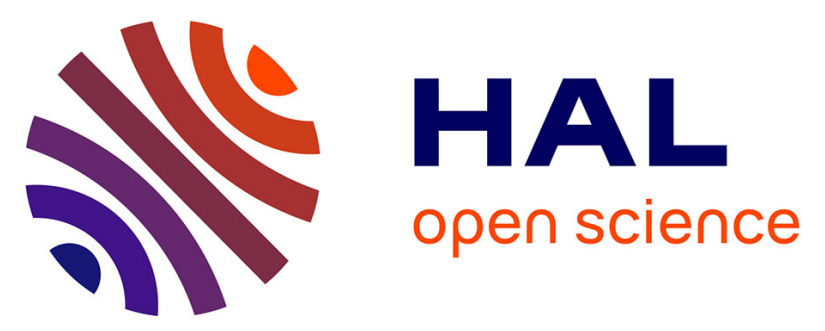

\title{
Risk analysis in project early phase taking into account the product lifecycle: Towards a generic risk typology for bidding process
}

\author{
Juan Diego Botero, Cédrick Béler, Daniel Noyes
}

\section{To cite this version:}

Juan Diego Botero, Cédrick Béler, Daniel Noyes. Risk analysis in project early phase taking into account the product lifecycle: Towards a generic risk typology for bidding process. 7th IFAC Conference on Manufacturing Modelling, Management, and Control, 2013, Jun 2013, Saint Petersburg, Russia. pp. 495-500. hal-00926534

\section{HAL Id: hal-00926534 \\ https://hal.science/hal-00926534}

Submitted on 9 Jan 2014

HAL is a multi-disciplinary open access archive for the deposit and dissemination of scientific research documents, whether they are published or not. The documents may come from teaching and research institutions in France or abroad, or from public or private research centers.
L'archive ouverte pluridisciplinaire HAL, est destinée au dépôt et à la diffusion de documents scientifiques de niveau recherche, publiés ou non, émanant des établissements d'enseignement et de recherche français ou étrangers, des laboratoires publics ou privés. 


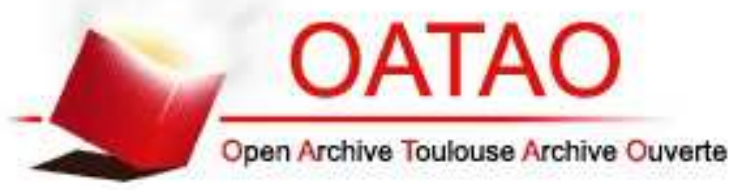

\section{Open Archive Toulouse Archive Ouverte (OATAO)}

OATAO is an open access repository that collects the work of Toulouse researchers and makes it freely available over the web where possible.

This is an author-deposited version published in: http://oatao.univ-toulouse.fr/ Eprints ID: 10040

\section{To cite this version:}

Botero, Juan Diego and Béler, Cédrick and Noyes, Daniel Risk analysis in project early phase taking into account the product lifecycle: Towards a generic risk typology for bidding process (2013) In: 7th IFAC Conference on Manufacturing Modeling, Management, and Control, 19 June 2013 21 June 2013 (Saint Petersburg, Russian Federation). 


\title{
Risk analysis in project early phase taking into account the product lifecycle: Towards a generic risk typology for bidding process
}

\author{
BOTERO Juan Diego. BELER Cédrick. NOYES Daniel \\ Laboratoire Génie de Production / INP-ENIT - University of Toulouse, \\ 47Avenue d'Azereix, 65016 Tarbes Cedex, France \\ E-mail: juan.boterolopez@enit.fr; cedrick.beler@enit.fr; daniel.noyes@enit.fr
}

\begin{abstract}
During the project early phase, considering a bidding process (BP), a client makes a request for a work or service to potential providers and then he chooses, by analyzing the responses, the one that will be accepted. From the bidder point of view, there are several risks when responding because he must develop a response based on a future development. Different in nature, these risks can be grouped into different categories. We propose a risk typology throughout the product lifecycle on which we rely to assist the bidder during BP via a methodology for decision support based on the experience acquired during past projects in order to detect, report and minimize the risks in current BP.
\end{abstract}

Keywords: bidding process (BP), risk analysis, product lifecycle, project management, lessons learned system (LLS).

\section{INTRODUCTION}

Call for tenders procedure is one of the most common ways to get contracts. Through this practice, a client company asks potential contractors a commercial proposal in response to specifications of his needs. This step called bidding process (BP) is very important because the decisions taken during this project early phase establish the conditions and responsibilities of the partners in the future collaboration.

$\mathrm{BP}$ is a risky practice. Indeed, beyond the obvious risk of non-acceptance of the offer, there is the risk of an incorrect assessment by the bidder of difficulties underpinned by the realization that could distort the offer nature. If it is accepted, the bidder may engage in a very penalizing process (overruns, non-compliance of technical requirements, noncompliance of deadlines...).

The objective of this work is to integrate the concepts of bidding process, risk management and product lifecycle (and project) to propose a methodology of risk management in the $\mathrm{BP}$ that relies on a generic mapping adaptable to different $\mathrm{BP}(\mathrm{s})$. Thus, the bidder will be able to make a proposal that meets the customer's expectations and that is consistent to its own needs and business constraints. In addition, it will put the customer at ease by showing him the company know-how and the implemented risk management strategies.

This document is organized in five sections:

- In section 2, we show the general principles of BP. We place the BP in a project management frame and we set it as the initial phase of the project.

- In the next section, the notion of risk is presented and this concept is extended to get our definition of BP risk.
- After presenting the reasons for its establishment, we propose in section 4, a taxonomy of BP risks. We show the importance of defining a general BP risk framework and each identified class is developed.

- The general approach to operate this risk mapping, and its coupling with a lessons learned system (LLS), is detailed in section 4. Here, we show the inclusion of this methodology into the decision-making process involved during the BP phases.

- Conclusion and perspectives are discussed in the last section and the results obtained in this work are detailed.

\section{BIDDING PROCESS AND PROJECT MANAGEMENT}

Bidding is a procedure that allows the client to choose the company best able to carry out a provision of works, supplies or services [Benaben, 09]. Each potential contractor commits resources and time to develop a proposal that may not be retained. This process is restrictive because, to be accepted, proposals must meet client specifications while remaining economically viable for the provider. These proposals are often dictated by the search for a compromise between minimum cost and production functions of specifications.

According to [Chalal et al, 06], BP is the first phase of the product lifecycle and includes the following steps:

- receipt of invitation to tender and customer specifications,

- feasibility study of the different options including primary technical and financial analysis,

- decision making coupled with strategic business decisions to follow through,

- development of the response, scoring and evaluation,

- negotiation. 
A key feature of BP is its short duration. Bidder often has little time to prepare the response to the client, which imposes severe constraints and expose him to several risks. In general, the first level of risk is that the offer is not accepted. Then, in case of acceptance, if the proposal was poorly developed, it may engage the bidder in an unsuitable process with catastrophic consequences.

The BP is conducted in a hypothetical manner since the product does not yet exist and the available information is often fragmented. We must therefore anticipate the potential development of the product in order to establish, in conjunction with financial and commercial means of the company, the proposal which will be sent to the client. For this purpose it is necessary to know not only the customer's requirements but also the methods and procedures of product development.

\subsection{BP Modelling}

A descriptive model of the BP proposed by [Benaben, 09] and based on the results of [Chalal et al, 06] synthesizes the successive activities carried out during BP (Figure 1).

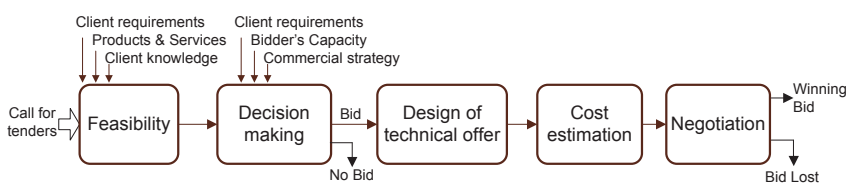

Figure 1. Bidding Process Model

This model includes an analysis phase (from call for tenders to decision making) in which the author splits the feasibility step from the related decision-making step. This decision is based on the ability of a provider to meet the client demand but also on its competitive and commercial strategy. The next phase is the design of technical offer, which is to define the proposal to the client. This phase is very important because the bidder must imagine the future design scenario to develop an adapted proposal that meets the client and their own constraints. Next, the cost estimation phase consists in establishing the bid price based on the resources that will be used and the expected gain. The negotiation phase consists in sending the offer to the client and the discussion on technical or economic points that may change. This last phase leads to the positive or negative response from the client.

\subsection{Link between BP and product / project lifecycle}

Our goal is to provide a methodology for identifying risks in BP. It is obviously necessary to consider the entire product / project lifecycle because decisions taken in BP phase may have consequences at different levels of this cycle (Figure 2). This integrated approach is comparable to systems engineering that is an interdisciplinary field for design and management of complex systems in the overall lifecycle [Goode et al, 57]. Indeed, BP corresponds to the initial phase of the product lifecycle and takes into account a "predictive simulation" of product development cycle (represented in Figure 2 by reduced white arrow in the BP).

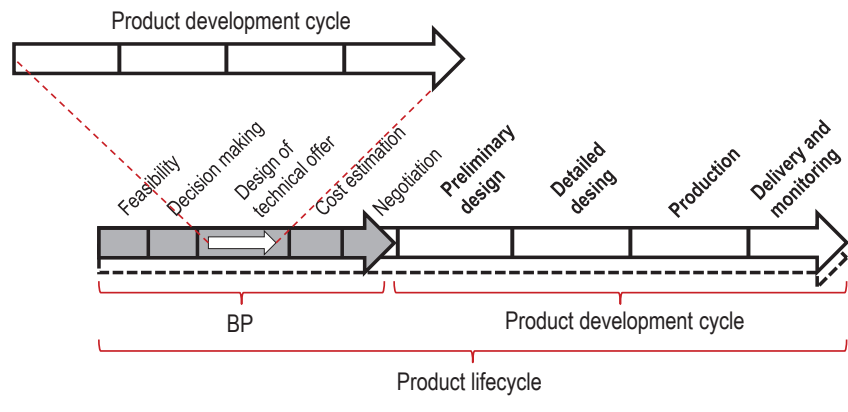

Figure 2. BP as the initial phase of product lifecycle

To define the successive actions that require the creation of a solution concept, we relied, without loss of generality, on the stages of project management that are very similar to those of BP. We made a comparison between BP phases and those of project management as described in [FD X50-118], [Desroches et al, 10], [Turner, 06] and [Nguyen et al, 08]. BP can be considered as an upstream phase of the project cycle. Therefore, the project risk, on which many studies have been conducted, should be taken into account in bidding process in conjunction with the BP specifics risks (see section 4).

\section{THE RISK CONCEPT AND ITS EVOLUTION TO THE BIDDING PROCESS RISK}

\subsection{Generic risk}

The risk concept has been studied for a long time and we can find in the literature many definitions depending on the scope. Most of these definitions include one or more of the following dimensions: event, cause, consequence, occurrence probability, severity, hazard, uncertainty, vulnerability, damage, likelihood and objective. Different risk works show that it is a multifaceted concept, but in general, the meaning is always the same. Each definition highlights one or more dimensions.

A classic view of risk is related to the perception causes / consequences of an unwanted event. The risk is associated to the occurrence of this event, correlated with the consequences it induces. In general, the risk is perceived as the combination of characteristics of unwanted events causes and consequences [Gouriveau et al, 04] as illustrated in Figure 3.

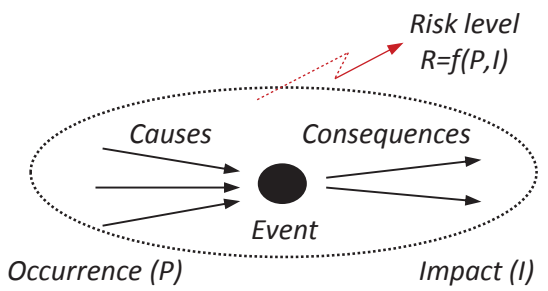

Figure 3. Classic risk model

The risk can manifest itself in several forms such an event, a measure, a state or an uncertainty [Sinou, 08]. A fifth form of risk manifestation has been discussed: the risk as a threat or hazard. In relation to this latter approach, the literature shows that the hazard is a potential of nuisance in terms of damage 
for a considered activity [Desroches et al, 10]. This potential is associated with a probability; the hazard is random in nature. When the potential of nuisance is deterministic (the probability is 1 ), it is considered as a threat.

The occurrence context of an unwanted event establishes the hazard and, depending on this, the consequences can be more or less serious. In Figure 4, our own view of risk is introduced. This model takes into account the external factors present in the context (that may increase the consequences) as an added element: the worsening causes. Note that the hazard can influence both the event occurrence and the impact of consequences.

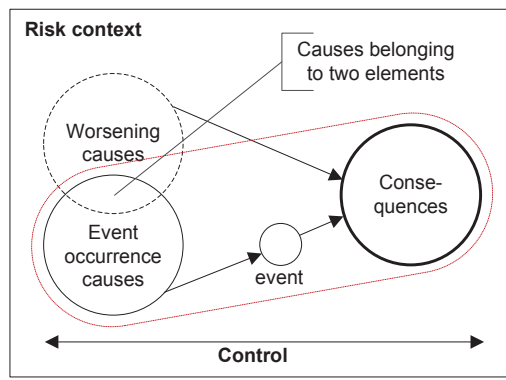

Figure 4. Proposed risk model

This model keeps the classical risk primitive depicted in Figure 3 (red dotted oval), but it adds worsening causes which are in a direct relationship with the impact level of consequences. Note that a worsening cause can also be an event occurrence cause. In addition, the "control" aspect has been integrated to represent the fact that control actions on causes and consequences can be carried out.

According to [Gouriveau et al, 04], risk is not only a single situation, but a set of linked situations to give the actual risk. In the model of Figure 5, we can see the sequence of risk situations (cascade effect), which represents all of the risks that are associated to a system from the initial causes to the final consequences. The risk is directly related to the exposure of a system to a hazard which results in a dangerous situation. In the absence of this exposition, the concept of risk has no meaning.

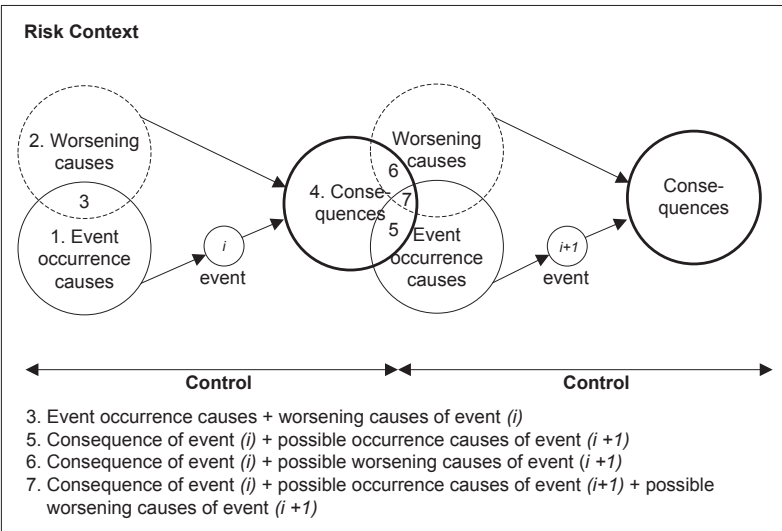

Figure 5. Sequence of risk situations

In Figure 5, an unwanted event (i) has a set of occurrence causes, worsening causes and consequences (as shown in Figure 4). The consequences of this event (i) can be part of both occurrence causes of a new event $(i+1)$ as worsening causes of this event, and so on.

In terms of project risks, [Desroches et al, 10] associates the risk to an event whose occurrence can frustrate the expectations of the project's objectives in terms of performance, cost and time. The [FD X50-117], defines project risk as "an event whose occurrence is uncertain and whose manifestation could affect the project objectives". According to [Nguyen et al, 08], project risk can be defined as "the possibility that an event occur whose occurrence would have consequences (positives or negatives) on the course of the project activity."

These three definitions show that project risk is associated with the occurrence of an event whose occurrence endangers the project objectives. The three most common project risks are: 1) non-achievement of specified performance in specifications, 2) late delivery of the product in relation to the contract date, 3) increased cost of product compared to the contract cost.

\subsection{BP Risk}

Our work leads to a vision of risk oriented towards the occurrence of unwanted events. Formally, the risk associated with the occurrence of the event $E$, is defined by two indivisible characteristics: the occurrence probability $(P)$ and the impact of its consequences $(I)$ in terms of gain or loss for the system relatively to a predetermined value scale.

In $\mathrm{BP}$, the objective is to provide an "optimal" response to the client in form of a solution principle. In order to achieve this goal, we must take into account the future development scenario to implement a risk management strategy [Botero et al, 12]. We have shown in section 2 that this process is very risky. In order to conduct risk management activities in BP, it is very important to define the risk in this context.

Given that BP is an upstream phase of project and that we take into account the whole product lifecycle for risk management, we rely on the generic risk definition and the project risk to establish our own definition of BP risk. We consider that BP risk is associated with the "occurrence of an unwanted event whose occurrence affects, firstly, acceptance objectives and, secondly (if the proposal is accepted), the objectives of quality, cost and timeliness".

\section{DEFINITION OF A BIDDING PROCESS RISK MAPPING}

Our goal in this work is first, to build a BP generic risk frame, which can be refined according to the system to be developed (product / service) and then, to use it in decision process involved in BP phases. Risks identification concerns the whole product lifecycle; it should lead to a structured risk model that will be reported in a parameterized form in BP.

There are few works about risk in BP context. The current works focus on the probability of winning or losing a tender but they do not consider the risks in the product lifecycle that should be taken into account to establish the response to the 
client. [Alquier et al, 00] however, proposes a risk classification in project early phase that takes into account future developments. He groups these risks into two classes: external risks, concerning situations affecting the gain of the call for tenders and, internal risks, related to situations affecting the success of the project.

We relied on this principle to establish a partition "external / internal risks" of all BP risks. However, our proposal differs from that of Alquier. In our approach, external risks $\left(\mathrm{R}_{\mathrm{Ext}}\right)$ include all risks whose causes comes from the bidder outside world in relation with the current BP. Internal risks $\left(\mathrm{R}_{\text {Int }}\right)$ include all risks whose causes are specific to the bidder company itself.

$\mathrm{BP}$ risks are therefore distributed as follow:

$$
\mathrm{R}_{\mathrm{BP}}=\mathrm{R}_{\mathrm{Ext}} \cup \mathrm{R}_{\text {Int }}
$$

The risk classes constituting these two categories are presented in Figure 6. We identify respectively client risk $\left(\mathrm{R}_{\mathrm{cl}}\right)$, competition risk $\left(\mathrm{R}_{\mathrm{cc}}\right)$ and environment risk $\left(\mathrm{R}_{\mathrm{ev}}\right)$ for external risks, and strategy risk $\left(\mathrm{R}_{\mathrm{st}}\right)$ project risk $\left(\mathrm{R}_{\mathrm{pj}}\right)$ and business risk $\left(\mathrm{R}_{\mathrm{bs}}\right)$ for internal ones, with:

$$
\begin{array}{ll} 
& R_{\text {Ext }}=R_{c l} \cup R_{c c} \cup R_{e v} \\
\text { and, } & R_{\text {Int }}=R_{s t} \cup R_{p j} \cup R_{b s}
\end{array}
$$

Below are described the six risks classes. Each class has its own specific risks subclasses. Note already that correlations may exist, depending on the considered case, between some risks of these different subclasses. However, whatever the considered situation, a classification of risks according to these different classes is always possible. These risks represent a company general knowledge. They are evaluated according to the bidder expertise and the previous cases. A risk can be taken into account with the same characteristics and parameters than past experiences or it can be adapted according to the new situation.

\subsection{Risks associated with the client}

Client risk $\left(\mathrm{R}_{\mathrm{cl}}\right)$ refers to hazardous events associated with the client and its credibility, its organization, the nature and expression of his needs. Six specific risks subclasses have been identified: 1) risks related to his needs resulting mainly from an unconsolidated definition; incomplete, inaccurate or evolving requirements and specifications; actual needs higher than estimated... 2) communication risks mainly correlated with the absence of a warned interlocutor, poor information quality, absence or delay of decision... 3) image risks arising from the client perception towards bidder and his expertise, 4) contractual risks corresponding directly to noncompliance with agreements, 5) risks related with the nature of $B P$ whose main problems are associated with the kind of market (public/private market), 6) financial resources risks arising from mismatches between financial means and need of the client, client insolvency...

\subsection{Risks associated with competition}

Competition risks $\left(\mathrm{R}_{\mathrm{cc}}\right)$ relate to hazardous events associated with competitors, their expertise, their practices and their structures. Four specific risks subclasses have been identified: 1) risks associated with skills as a direct result of competitors having a better knowledge or a better understanding of the problem, 2) confidentiality risks mainly caused by information leaks between the client and a competitor, resulting in the dissipation of know-how, 3) risks related with "hardening" of client requirements caused by the appropriation of other bids, 4) malevolence risks whose problems are related to competitors malicious actions to the tender.

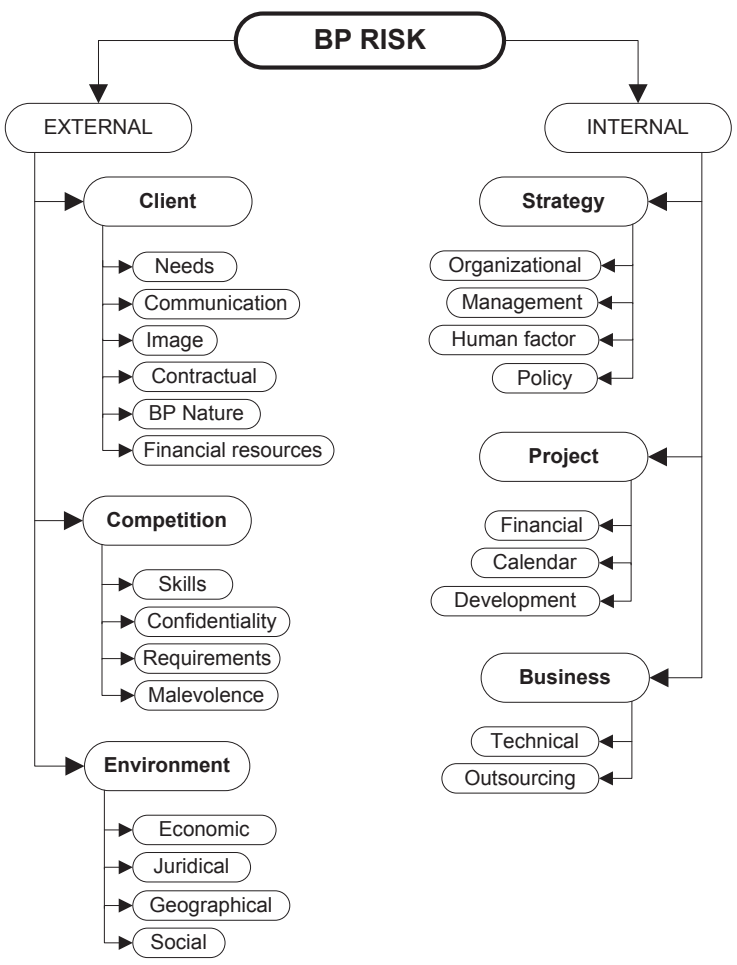

Figure 6. Bidding Process Risk Mapping

\subsection{Risks associated with environment}

Environmental risks $\left(\mathrm{R}_{\mathrm{ev}}\right)$ relate to hazardous events linked to the context and associated with economic, regulatory, geographical and social factors. Four specific risks subclasses have been identified: 1) economical risks whose main problems are associated with moving market conditions and fluctuating costs of equipment, raw materials... 2) legal risks associated with non-compliance with regulations and standards, 3) geographical risks whose current issues are the difficulty of access to the project site, bad roads, constraining weather conditions... 4) social risk in relation to political and social instability of the company and the area.

\subsection{Risks associated with the strategy}

Strategy risks $\left(\mathrm{R}_{\mathrm{st}}\right)$ correspond to hazardous events associated with the bidder strategy actions. There are five specific risks subclasses: 1) organizational risks resulting from inappropriate structures, lack of well-defined procedures, 
lack of risks analysis, use of new technologies or materials, use of legacy technologies, 2) management risks correlated with the absence of management plan, unsuitable call for outsourcing, lack of coordination and promotion meetings... 3) human factor risks arising from the deficiency of negotiator skills, non-consultation with the technical team to meet the call for tenders, inadequate team to competence plan, partial unavailability of key employees, 4) commercial risks in relation to delay of order supplies, absence of a reliable supplier base, adoption of technical solutions of a provider who holds a monopoly... 5) internal policy risks often linked to the lack of important elements in the company policy such as dependability (RAMS), experience feedback (EF)...

\subsection{Risks associated with the project}

Project risks $\left(\mathrm{R}_{\mathrm{pj}}\right)$ are associated with the project development, when the technical proposal has been accepted. They correspond to hazardous events related to the conduct of the project and the means to achieve it. Three specific risks subclasses have been identified: 1) financial risks associated with sub-economic assessment or acceptance of an insufficient budget, non-monitoring gaps between budget and actual financial situation, delays in client's payment, 2) calendar risks linked to underestimated delays or the acceptance of short deadline, non-contribution of partners in the preparation of schedules, absence of analysis trends of advancement, no updated schedules... 3) development risks whose main problems are associated with the non-verification of adequacy between existing means and client needs, supplier problems (delivery delays or non-conforming supplies), lack of technical solutions that can support changes, absence of techno-economic studies of different options and lack of consideration of logical constraints.

\subsection{Risks associated with the business}

Business risks $\left(R_{b s}\right)$ refer to hazardous events related to know-how, involved technical resources and effects on the expected performance of the delivered product. Two specific risks subclasses have been identified: 1) technical risks, which are a very important subclass and which result from human error (incorrect application of business rules, inappropriate treatment...), lack of expertise in the field, malfunction of equipment, unmatched materials... and all risks directly related to the product development, 2) outsourcing risks, which take an important part of technical risks mentioned above, but this time in the outsourcing context.

\section{GENERAL APPROACH TO EXPLOIT THE RISK MAPPING}

Among the different risk classes described in section 4 , the first four categories $\left(\mathrm{R}_{\mathrm{cl}}, \mathrm{R}_{\mathrm{cc}}, \mathrm{R}_{\mathrm{ev}}\right.$ and $\left.\mathrm{R}_{\mathrm{st}}\right)$ represent $\mathrm{BP}$ generic risks (specific to the process itself), while the last two categories $\left(\mathrm{R}_{\mathrm{pj}}\right.$ and $\left.\mathrm{R}_{\mathrm{bs}}\right)$ represent risks related to $\mathrm{BP}$ "object" (dedicated risk). In this section, a matching proposal of this analysis with a lessons learned system (LLS) is introduced to make the BP easier to deal with.

We rely on risk mapping presented in section 4 , to develop a generic risk model to be considered in the BP phase. We illustrate the approach on the diagram in Figure 7A. This involves three steps:

1) Projection of "mapped" risks in section 4 on the different $\mathrm{BP}$ and product lifecycle phases (shown schematically in Figure 7A by the distribution of unwanted events $(N)$ via the black arrows).

2) Transposition of risks of the product development cycle to the BP phases (shown schematically in Figure 7A by transfer of unwanted events to BP through the red arrows).

3) Parameterization of model to the considered BP.

Steps 1 and 2 provide the generic BP risks model (different formalization tools can be used: conceptual graphs, workflow models...). Step 3 provides a model instance from which will be conducted risk analysis itself.

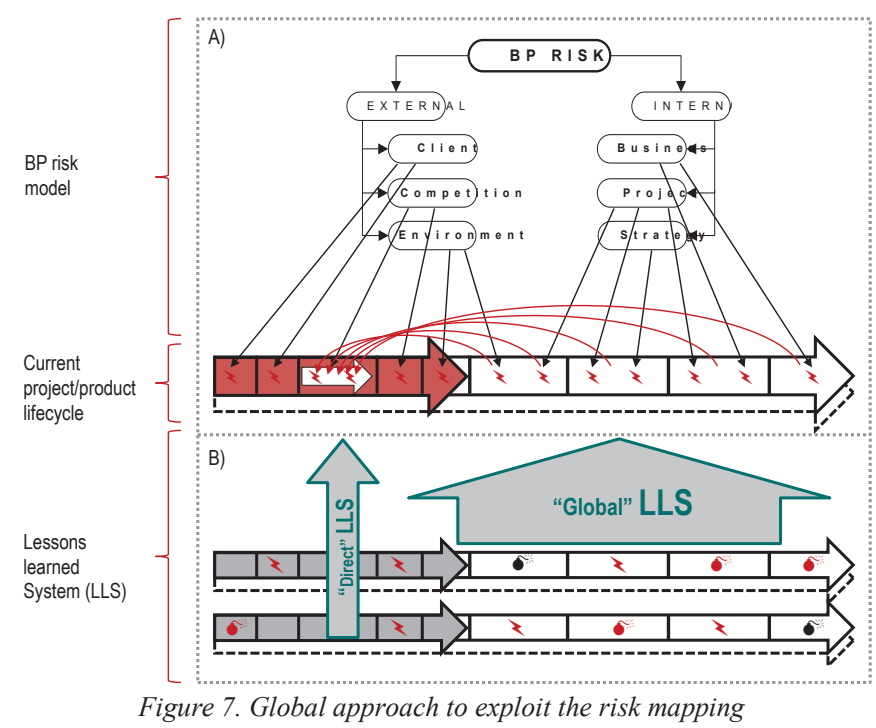

We are not going further in the description of BP risks model because an essential element of our approach is introduced: the coupling of this model to a lessons learned system (Figure 7B).

Lessons learned system (LLS) is a structured approach for the capitalization and exploitation of information from the analysis of positive and/or negative events in order to reduce the repetition of errors and promote successful practices [Rakoto et al, 02]. The purpose of LLS is to rely on the analysis of a fact or past events to reuse the underlying knowledge. We call "lessons learned base" all the experiences collected for reuse. Three types of LLS activities can be readily distinguished:

- capitalization activities, concerning the supply of experience and knowledge base, 
- processing activities, related to the analysis and maintenance of stored experiences and their transformation into knowledge,

- exploitation activities, in relation to the use of experiences and knowledge base, whether it is used directly (a problem has been solved and its solution is directly applied or adapted) or generally (several problems have been solved and it is possible to deduce rules to prevent them breed).

The main advantage of LLS is the ability to recover the knowledge acquired in past experiences to make use of it when facing a new situation; in our study, it is a new call for tenders.

Figure 7B shows that we consider two LLS in order to operate the company risk knowledge: 1) a direct LLS bearing on the different past BP(s), 2) a global LLS applied to the different phases of product life cycles of past projects.

The direct LLS allows capitalizing risks that have been identified during the past $\mathrm{BP}$ and exploiting this knowledge to establish the corresponding risks in the current BP. The global LLS allows identifying risks occurring in the different phases of past projects and transposing them on the product lifecycle of the future project associated with the current BP.

Note that this "bottom-up approach", where are exploited specific passed knowledge to establish the current BP risks, is quite complementary to the "top-down approach" exposed at the beginning of this section, which exploit the projection and the transposition of risks mapped as a generic knowledge.

In the end, risk management during the current $\mathrm{BP}$ will be based on all information resulting from the two approaches (top-down for generic BP risks model and bottom-up for lessons learned system "LLS”).

$B P$ risks model derived from the general mapping, is a generic knowledge that allows identify potential risks at different stages of BP and product lifecycle. The exploitation of the information extracted from the passed $\mathrm{BP}(\mathrm{s})$ (extended to product lifecycles associated) allows strengthening the current BP model. At this level, a similarity search between the characteristics of past cases and those of the current BP (linked to the context, the client, the object of BP...) will allow to retain only significant past experiences in order to adapt them to the BP risks model of current case.

\section{CONCLUSION}

In this paper, a practical approach to risk analysis in BP has been introduced. We insisted especially in the identification and characterization aspects of these risks by relying on two important elements: risk mapping in this particular context (BP), and exploitation of lessons learned systems (LLS) applied to the past $\mathrm{BP}(\mathrm{s})$ and product life cycles associated.

The proposed risk mapping might not be exhaustive. It will obviously undergo changes depending on the knowledge contributions from the LLS, which will enhance the BP risks model. Another usefulness of this model will be on the development of specific treatments for the identified risk classes.

Finally, it is necessary to provide the appropriate mechanisms to extract knowledge from a lessons learned base (experience carried out by similar past cases) and also to transpose the results in a meaningful way for the BP under evaluation.

\section{REFERENCES}

Alquiers, A.M., Cagno, E., Caron, V., Leopoulos, V. and Ridao, M.A. (2000). Analysis of external and internal risks in project early phase. Proceeding of PMI Research Conference, pp. 147-155.

Benaben, A. (2009). Méthodologie d'identification et d'évaluation de la sûreté de fonctionnement en phase de réponse à appel d'offre. $\mathrm{PhD}$ thesis, National Polytechnic Institute of Toulouse (France).

Botero, J.D., Béler, C., Noyes, D. and Geneste, L. (2012). Integration of experience feedback into the product lifecycle: An approach to best respond to the bidding process. Information Control Problems in Manufacturing, volume 14, pp. 1095-1100.

Chalal, R. and Ghomari, A.R. (2006). An Approach for a Bidding Process Knowledge Capitalization. Proceedings of world academy of science, Engineering and technology, volume 13. ISSN 1307-6884.

Desroches, A., Marle, F., Raimondo, E. and Vallée, F. (2010). Le management des risques des entreprises et de gestion de projet. Hermes Science Publications. Paris.

FD X50-117. (2003). Project management - Risk management - Management of the risks of a project.

FD X50-118. (2005). Project management Recommendations for the management of a project.

Goode, H. and Machol, R.E. (1957). System Engineering: An introduction to the design of large-scale systems. McGraw-Hill. New York.

Gouriveau, R. and Noyes, D. (2004). Risk managementdependability tools and case-based reasoning integration using the object formalism. Computers in industry, volume 55, pp. 255-267.

Nguyen, T.H. and Gourc, D. (2008). Towards a model for assessing risk impact on project planning. 22nd IPMA World congress: project management to run. Roma, Italy.

Rakoto, H., Hermosillo, J., and Ruet, M. (2002). Integration of experience based decision support in industrial processes. IEEE International Conference on Systems, Man and Cybernetics, volume 7, pp. 6-11.

Sienou, A. (2008). A Method for Integrated Management of Process-risk. Proceedings of GRCIS, volume 339, pp. 17-30.

Turner, J. (2006). Towards a theory of project management: The nature of the project governance and project management. International Journal of Project Management, volume 24, pp. 93-95. 